\title{
Robotic mitral valve surgery: overview, methodology, results, and perspective
}

\author{
W. Randolph Chitwood Jr $\mathbf{r}^{1,2,3}$
}

${ }^{1}$ Emeritus Chairman, Department of Surgery, Brody School of Medicine, Greenville, NC, USA; ${ }^{2}$ Founding Director, East Carolina Heart Institute, East Carolina University, Greenville, NC, USA; ${ }^{3}$ Visting Professor, University of Virginia, Charlottesville, VA, USA

Correspondence to: W. Randolph Chitwood Jr, MD, (D.Sc.-Hon), FACS, FACC, FRCS (England). 146 East Longmeadow Road, Greenville, North Carolina 27858, USA. Email: chitwoodw@ecu.edu.

Robotic mitral valve repair began in 1998 and has advanced remarkably. It arose from an interest in reducing patient trauma by operating through smaller incisions with videoscopic assistance. In the United States, following two clinical trials, the FDA approved the daVinci Surgical System in 2002 for intra-cardiac surgery. This device has undergone three iterations, eventuating in the current daVinci XI. At present it is the only robotic device approved for mitral valve surgery. Many larger centers have adopted its use as part of their routine mitral valve repair armamentarium. Although these operations have longer perfusion and arrest times, complications have been either similar or less than other traditional methods. Preoperative screening is paramount and leads to optimal patient selection and outcomes. There are clear contraindications, both relative and absolute, that must be considered. Three-dimensional (3D) echocardiographic studies optimally guide surgeons in operative planning. Herein, we describe the selection criteria as well as our operative management during a robotic mitral valve repair. Major complications are detailed with tips to avoid their occurrence. Operative outcomes from the author's series as well as those from the largest experiences in the United States are described. They show that robotic mitral valve repair is safe and effective, as well as economically reasonable due to lower costs of hospitalization. Thus, the future of this operative technique is bright for centers adopting the "heart team" approach, adequate clinical volume and a dedicated and experienced mitral repair surgeon.

Keywords: Robot; robot-assisted; mitral valve; repair; daVinci system

Submitted Jan 31, 2016. Accepted for publication Mar 17, 2016.

doi: $10.21037 /$ acs.2016.03.16

View this article at: http://dx.doi.org/10.21037/acs.2016.03.16

He who is fixed to a star does not change bis mind.

_Leonardo da Vinci

\section{Evolutionary overview}

With the development and improvement of endoscopic vision in the late 1970s, the notion of laparoscopic operations was spawned and then developed rapidly, despite early reservations by most surgeons. This skepticism was gradually overcome as many traditional general surgical, gynecological and urological operations were replaced rapidly by less invasive and/or endoscopic operations. During this era, cardiac surgery had evolved so well using sternotomy incisions that there seemed to be no incentive for cardiac surgeons to adopt either secondary vision or less invasive incisions. Non-cardiac thoracic surgeons were the first to embrace this disruptive methodology and they proved that major pulmonary operations could be done safely and effectively using thoracoscopic techniques.

The idea of minimally invasive cardiac surgery emanated from the "Heartport Era" with the development of new innovative aortic occlusive devices, long-shafted instruments and ports for cardiac access $(1,2)$. These developments issued the clarion call that minimally invasive cardiac surgery was possible and that surgeons must begin 

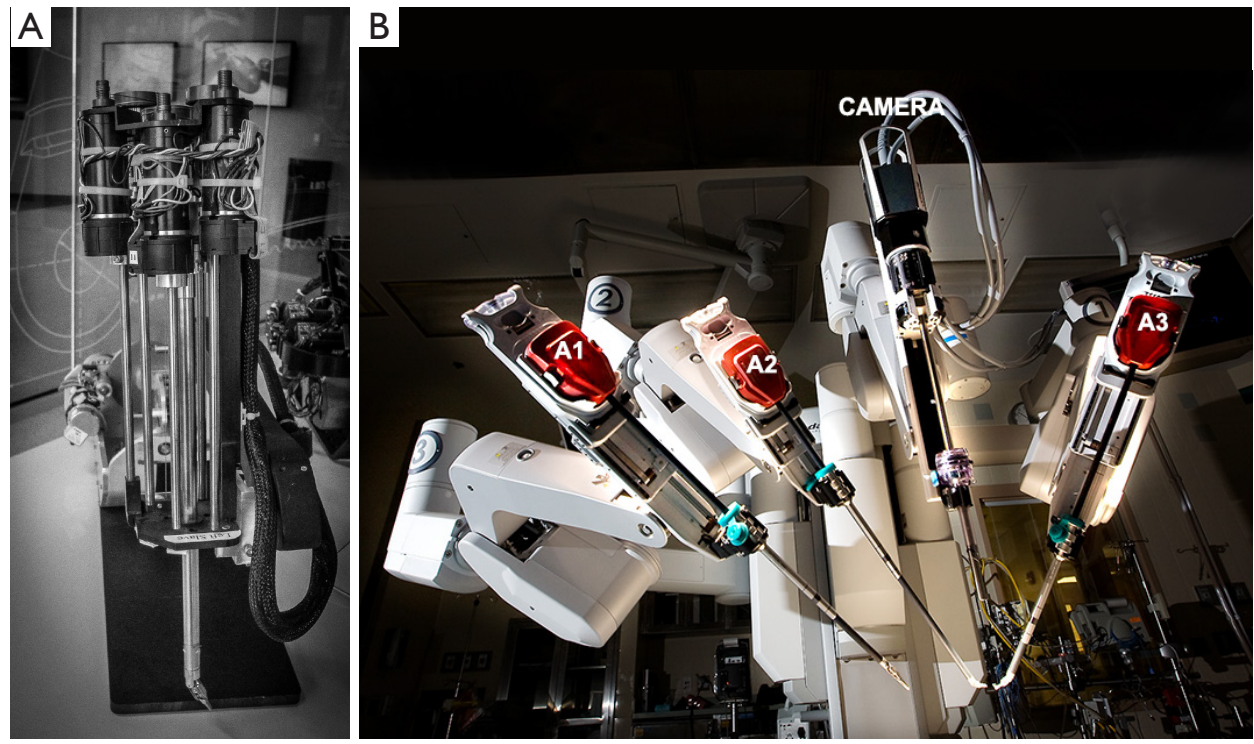

Figure 1 (A) "Lenny" [1995]—The articulated robotic arm predicate of the daVinci System; (B) the third generation daVinci SI instrument arm system (A1-A3) used by the author [2015].

to innovate and develop this area. Thereafter, other less invasive methods were developed to perform minimally invasive heart valve surgery through alternate chest and sternotomy incisions by using modifications in cannulation and sternal access (3). It was time for videoscopic vision to play a major role in cardiac surgical procedures (Video 1).

The concept of operating inside the heart with indirect vision is not new. Duff Allen and Evarts Graham developed a cardioscope and tested it in animals in 1922 (4). Harken experimented with intra-cardiac visualization techniques in 1943 (5). In 1958, Sakakibara endoscopically observed aortic valves and septal defects and predicted that valve operations could be treated using cardioscope vision (6,7). Kaneko (1995) used videoassistance through a sternotomy to aid in mitral repairs and commissurotomy (8). Carpentier performed the first minimally invasive videoscopic mitral valve repair in February of 1996 (9). Two months later, we did the first minimally invasive mitral valve replacement using secondary two-dimensional (2D) vision (10). Early series by our team, Mohr, and Vanermen proved feasibility, safety and efficacy to perform mitral repairs using $2 \mathrm{D}$ videoscopic vision and long shafted instruments (11-13). It became clear to many of us that surgeons could operate effectively through port-like incisions using assisted vision, albeit with limited ergonomic dexterity.

Interest in surgical robots began at the Defense Advanced
Research Projects Agency (DARPA) in collaboration with the Stanford Research Institute. In the early 1990s, they developed the progenitors of current robotic platforms (14). At the time, DARPA initially funded the development of Aesop 3000 (a voice-activated robotic camera positioner), which was the first robotic surgical device approved by the FDA. It became the founding device for Computer Motion, Inc. In 1995, a start-up company, Intuitive Surgical Devices, Inc., acquired tele-presence surgery technology from the Stanford Research Institute. Lenny was the predicate device to the modern day daVinci Surgical System (Figure 1), involving was an articulated arm with a wrist that had seven degrees of motion freedom. Computer Motion launched Zeus in 1997. In May of 2000, Grossi performed a partial mitral valve repair with it (15). The latter device did not have the same range of motion or video quality as daVinci. It was discontinued in 2003, following litigation and the merger of the Intuitive Surgical and Computer Motion companies.

In early 1997 at the Intuitive Surgical, Inc. plant, I began working with the prototype of the daVinci System (Figure 2). In May of 1998 Carpentier and Mohr, using this early device (Figure 3), independently performed the initial daVinci mitral valve repair operations $(9,16)$. In 1999 the daVinci System became commercially available for clinical use in Europe. That year, our center purchased the first system in the United States for laboratory training 

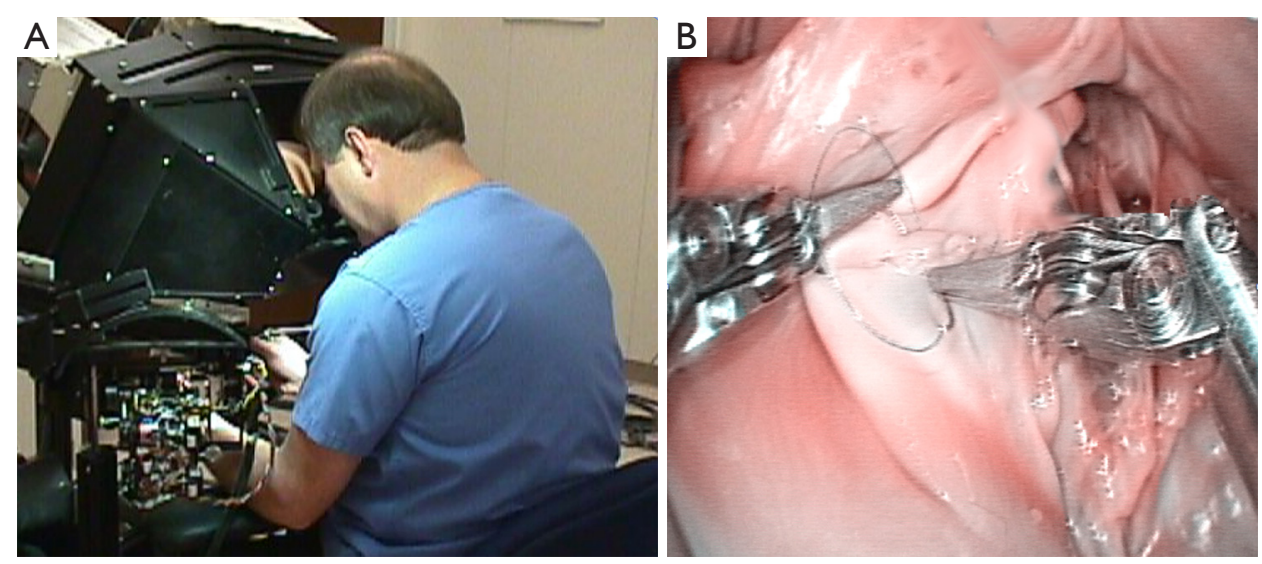

Figure 2 First prototype of the daVinci System [1997]. (A) The author testing the first surgeon console; (B) early instrument wrists for the daVinci prototype.

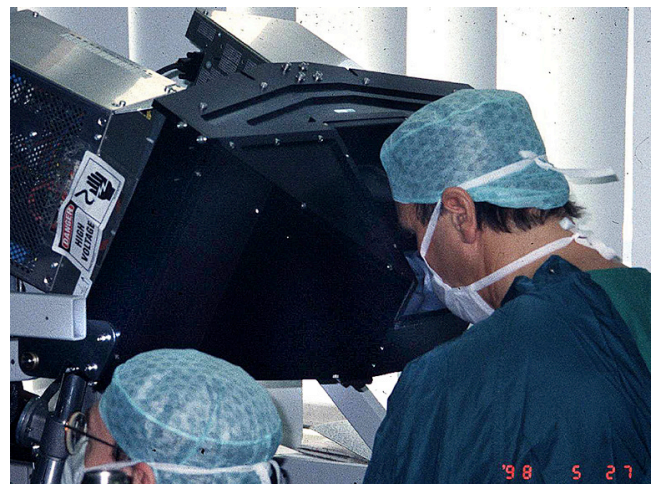

Figure 3 Friedrich Mohr MD performing the first series of mitral valve repairs with the daVinci prototype at the Leipzig Heart Center in late May of 1998.

our team. In May of 2000 we performed the first complete robot-assisted, minimally invasive, mitral valve procedure (RMVP) repair under an FDA safety and efficacy trial using the first commercial daVinci System (Figure 4) (17). A multicenter trial then eventuated in approval for intracardiac use (mitral surgery) in 2002 (18).

Thereafter, early adopters, including our team and those of Murphy, Smith, Siwek, Mihalievic, and Trento, continued to prove the benefits of robotic mitral repair surgery (19-25). Recently, Suri and Mihaljevic independently have shown economic, social, and quality of life benefits of robotic mitral valve repairs (26-28). A number of early programs started and stopped doing robotic cardiac surgery, citing labor intensity, cost, poor outcomes, team issues and low clinical volume.
Nevertheless, recent large series have proven the benefits to both patients and surgeons, and that this technology is ideal for performing mitral surgery (29-37). Part of the continued success relates to the evolution of the daVinci System and custom instruments. Three earlier versions culminated in the present daVinci XI system, which has an advanced visualization system, improved ergonomics and a programmable instrument cart (Figure 5).

\section{Patient selection}

RMVP is appropriate for patients with both degenerative and functional mitral valve disease. Robotic mitral replacement has been reserved for patients having rheumatic or sometimes functional disease. Patients considered for a robotic repair or replacement, should have the same indications that are outlined in either the 2014 ACC/ AHA (United States) or 2012 ESC/EACTS (European) Guidelines (38,39). They should be informed of alternative approaches including a traditional sternotomy. Moreover, they must understand that there is a small possibility of requiring a conversion sternotomy. Operative risks, age, fragility, and the complexity of mitral pathology should be considered when selecting patients for a RMVP.

\section{Preoperative screening}

Candidates should be screened carefully for peripheral vascular and coronary artery disease as well as pulmonary conditions. In most patients, either a broad spectrum computed tomography (CT) scan and/or coronary 

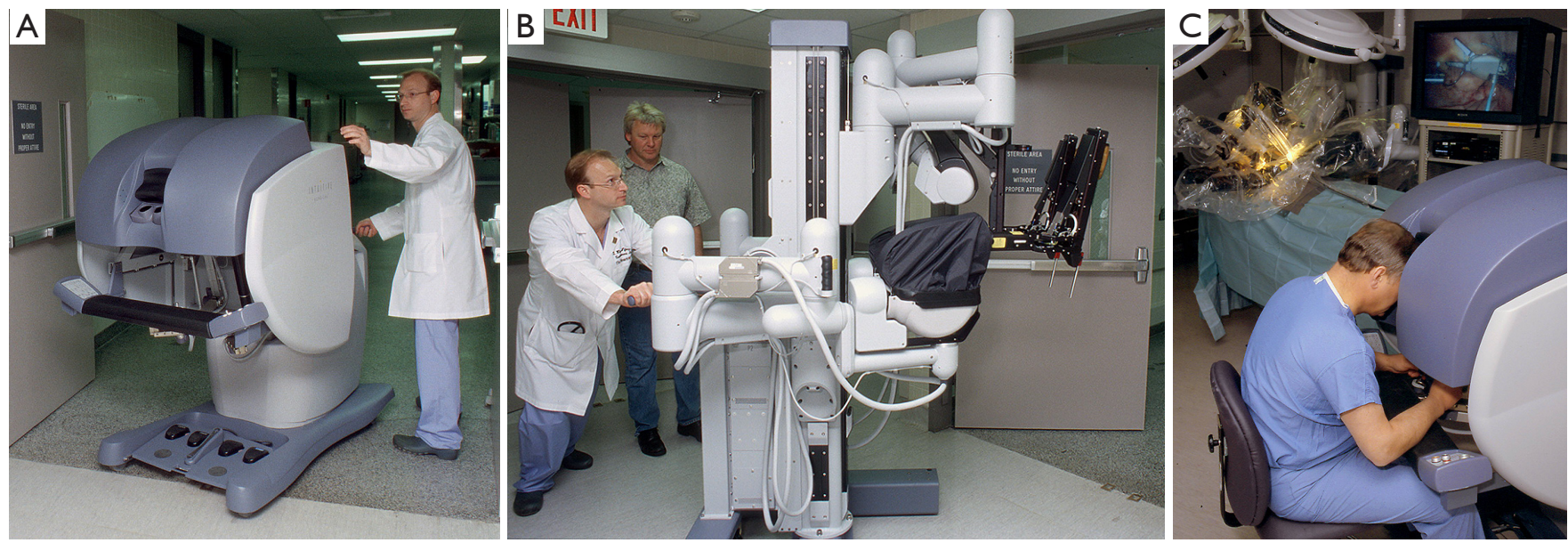

Figure 4 First commercial daVinci System purchased in the United States [1999]. This was used for the initial FDA mitral repair clinical trials. Dr. L. Wiley Nifong is shown unloading the (A) surgeon console and (B) instrument cart (C) the first daVinci System setup in the laboratory. The author is shown at the operating console.
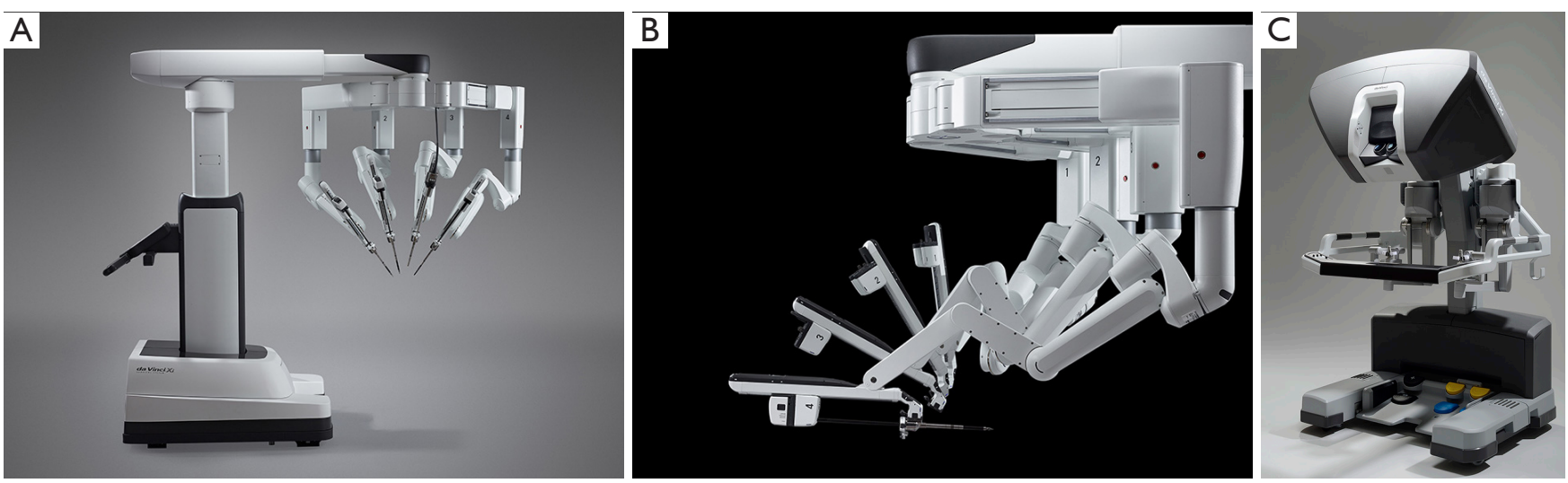

Figure 5 The daVinci XI surgical system. (A) The new instrument cart is pictured and shows the (B) additional "elbow" joint that enables better tableside positioning; (C) surgeon operating console.

angiogram should be performed. Pulmonary function tests should be performed in heavy smokers and those with obstructive disease. Both trans-thoracic and transesophageal echocardiography are ideal to determine detailed valve pathology, ventricular function, and the presence of pulmonary hypertension. If the latter is present, a right heart catheterization may be indicated.

\section{Contraindications}

Both relative and absolute contraindications are listed in Tables 1 and 2. In the presence of multiple comorbidities, the author suggests using traditional incisions, perfusion and myocardial protection techniques. Some relative contraindications can be managed by selecting alternate methods for perfusion and myocardial protection (e.g., axillary artery cannulation, hypothermic ventricular fibrillation). Moreover, preoperative coronary stenting has obviated the need to abandon consideration for a RMVP.

\section{Operative planning}

The standard Carpentier mitral nomenclature is used when describing valve pathology (40). Either an excellent trans-thoracic (TTE) or trans-esophageal (TEE) echocardiographic study should be done to determine 


\begin{tabular}{l} 
Table 1 Contraindications to robotic mitral valve repair and \\
replacement \\
\hline Previous right thoracotomy \\
Severe pulmonary dysfunction \\
Myocardial infarction or ischemia $<30$ days \\
Coronary artery disease-requiring CABG \\
Severe generalized vascular disease \\
Symptomatic CVD or stroke $<30$ days \\
Poor right ventricular function \\
Pulmonary hypertension (fixed $>60$ torr) \\
Significant aortic stenosis or insufficiency \\
Severe annular calcification (repairs) \\
Severe liver dysfunction \\
Significant bleeding disorders \\
\hline CABG, coronary artery bypass grafting; CVD, cerebrovascular \\
disease.
\end{tabular}

Table 2 Relative contraindications to robotic mitral valve surgery

Previous sternotomy
Moderate pulmonary dysfunction
Asymptomatic CAD (treated)
Coronary artery disease-requiring PCI
Limited peripheral vascular disease
Asymptomatic CVD
Poor left ventricular function (EF <30 \%)
Pulmonary hypertension (variable $>60$ torr)
Mild to moderate aortic stenosis or insufficiency
Moderate annular calcification
EF, ejection fraction; CAD, coronary artery disease; $\mathrm{PCI}$,
percutaneous coronary intervention; CVD, cerebrovascular disease.

operative necessity and to guide the operative plan. In the operating room a 2D TEE with detailed studies is essential. Three-dimensional (3D) studies are additive and necessary for creating valve topographic image models. The direction of each jet (leak) should be mapped with both mobility and level of leaflet prolapse/restriction determined. Each leaflet segment $\left(\mathrm{P}_{1}-\mathrm{P}_{3}, \mathrm{~A}_{1}-\mathrm{A}_{3}\right)$ should be measured with specific attention to both the $\mathrm{A}_{2}$ length and $\mathrm{P}_{1}-\mathrm{P}_{3}$ heights
Table 3 Trans-esophageal echo repair planning

Lengths (mm) of $A_{2}, \& P_{1}, P_{2}, P_{3}$

Annular diameter and geometry-tricuspid and mitral

Definition of posterior leaflet clefts and independence

Direction and intensity of leak jets

Planar angle between mitral and aortic annulus

Degree $(\mathrm{mm})$ of leaflet segmental prolapse or restriction

"Septal knob" thickness (mm)

Aortic outflow tract size-coaptation-septal distance

Reconstructed topographic mitral valve model

(annulus to coapting edge). Additionally, the planar angle between the aortic and mitral valve annulus as well as septal thickness are important to help determine the risk of systolic anterior leaflet motion and outflow obstruction. Finally, the annular diameter, outflow tract septal thickness and coaptation point to septal (C-Sept) distances should be measured. Table 3 shows suggested echocardiographic information that is helpful in planning and performing a RVMP (41).

\section{Operative management}

The Atlas of Robotic Cardiac Surgery provides many details regarding anesthesia, the robotic setup and conduct of both a RMVP and replacement at several well-known centers (42). Moreover, Cardiopulmonary Bypass and Mechanical Support: Principles and Practice provides precise details of our method of cardiopulmonary perfusion (43). The following outlines the East Carolina Heart Institute (ECHI) protocol and sequence for performing a RMVP (44):

(I) After double lumen intubation, a Swan-Ganz catheter, right internal jugular venous drainage cannula and a 3D transesophageal (TEE) probe are inserted;

(II) Detailed 3D TEE echo studies are done and a topographic computer valve model is generated (Table 3);

(III) Venous drainage is provided via the right femoral and internal jugular veins. Retrograde arterial inflow is established via the right femoral artery, or the right axillary artery in the presence of aorto-iliac disease; 

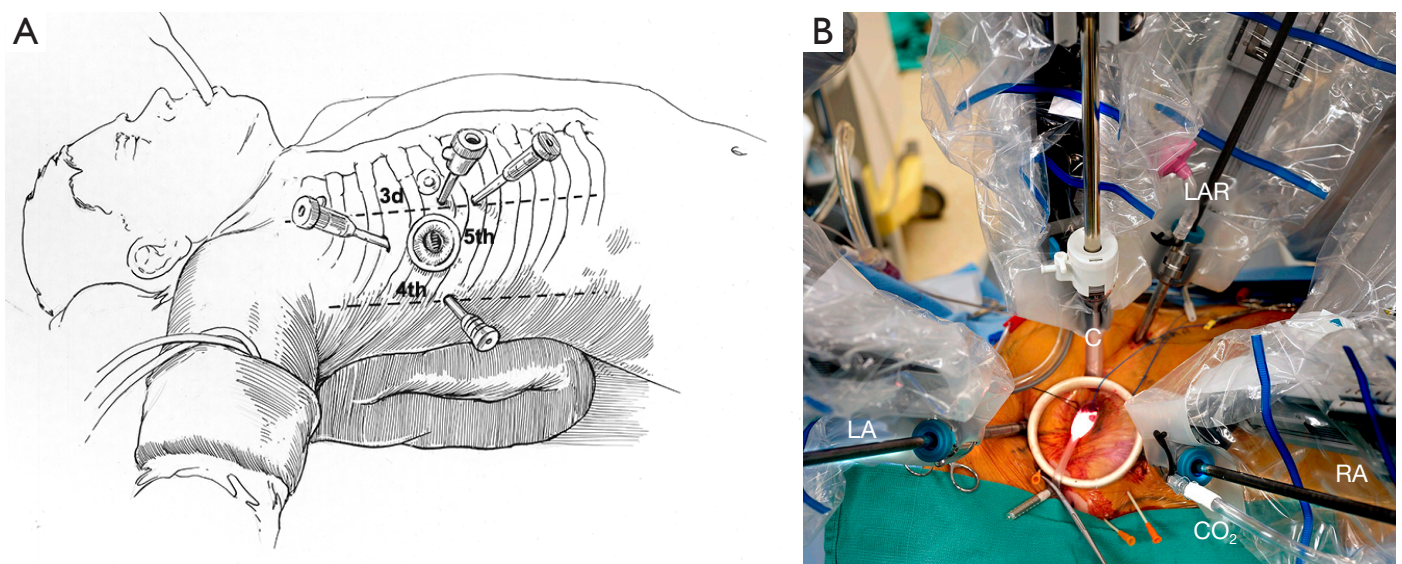

Figure 6 (A) Port placement for a robotic mitral valve repair; (B) articulated instruments and the 3-D camera have been inserted in preparation for a robotic mitral valve repair. The cross clamp has not been placed yet. LA, left arm; RA, right arm; LAR, left atrial retractor; C, camera, $\mathrm{CO}_{2}$ cannula is hooked to the right arm. (Permission of Author-Atlas of Robotic Cardiac Surgery).
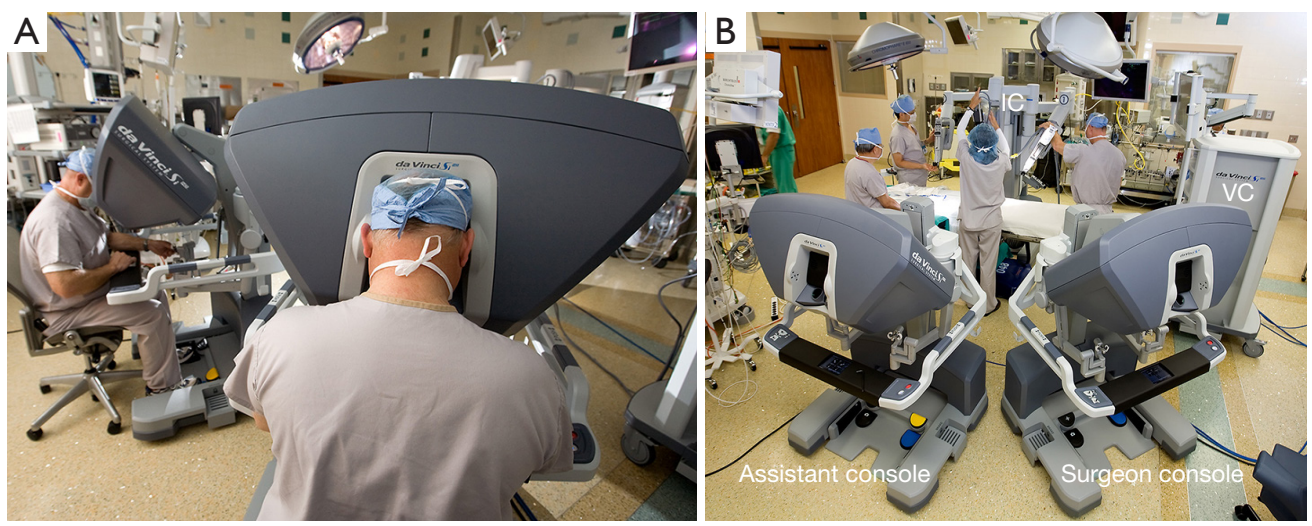

Figure 7 (A) The surgeon and assistant/learner are seen at the daVinci SI operating console; (B) the daVinci SI and XI both have dual surgeon operating console capabilities. The instrument (IC) and vision carts (VC) are shown.

(IV) A 2.5-cm fourth intercostal space (ICS) working port is made in the anterior axillary line;

(V) Robotic arm trocars are placed in the third and fifth ICS and a camera trocar is placed anterior to the working port in the fourth ICS. A trocar is inserted in the submammary fifth ICS for insertion of the dynamic mitral retractor. Left and right robotic instruments, 3D camera and retractor are inserted (Figure 6);

(VI) The operating surgeon does the complete operation from the console (Figure 7);

(VII) After perfusion is established $\left(28^{\circ} \mathrm{C}\right)$ and both pericardial entry and suture retraction are established, an antegrade cardioplegia needle/vent is placed in the ascending aorta just distal to the right coronary artery;

(VIII) A trans-thoracic aortic clamp is passed through the chest wall in the second or third ICS in the posterior axillary line and positioned around the aorta through the transverse sinus (Figure 8);

(IX) After aortic clamping and cardiac arrest with HTK-Bretschneider's solution, a left atriotomy is made, and the mitral valve exposed with the dynamic retractor (Figure 9);

(X) Robotic mitral valve replacements are done using the same setup as described for RMVP. Figure 10 shows a bioprosthetic replacement using Cor-Knot suture fasteners (LSI solutions, Victor, NY, USA); 

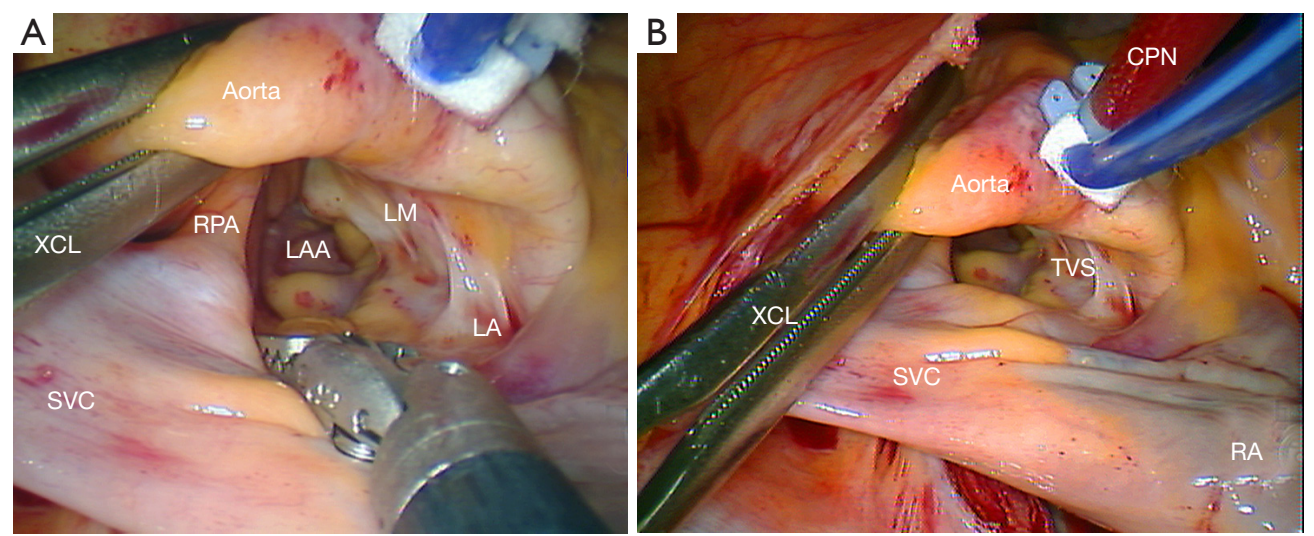

Figure 8 The transthoracic aortic cross clamp has been passed through the transverse sinus and deployed. (A) Details of the transverse sinus are shown; (B) the transthoracic cross clamp (XCL) is shown with respect to the cardioplegia needle (CPN). XCL, transthoracic cross clamp; RPA, right pulmonary artery; SVC, superior vena cava; LAA, left atrial appendage; LA, left atrial roof; LM, Left main coronary artery; TVS, transverse sinus.
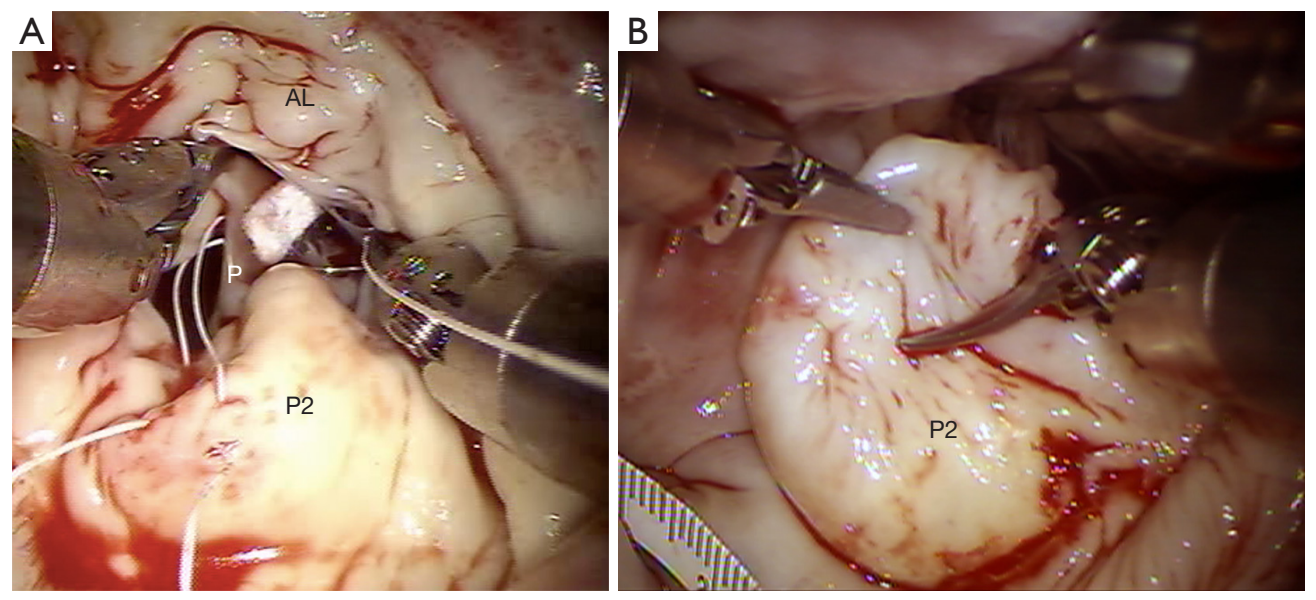

Figure 9 Robotic mitral repair. (A) Example of neochord implantation between the anterior papillary muscle $\mathrm{P}$, and $\mathrm{P}_{2}$ of the posterior leaflet; (B) example of a partial $\mathrm{P}_{2}$ resection. $\mathrm{AL}$, anterior leaflet.
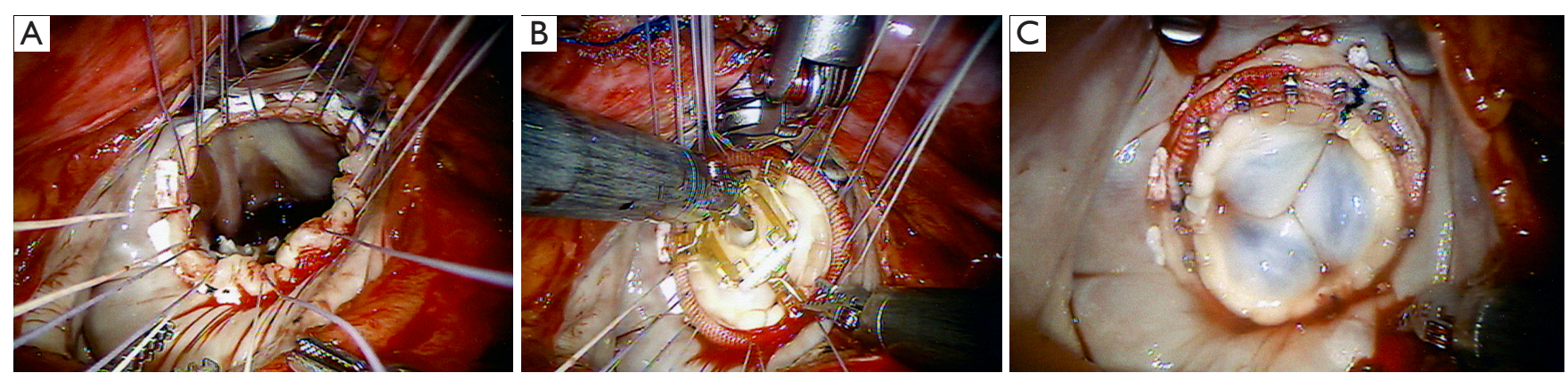

Figure 10 Robotic mitral replacement. (A) supra-annular sutures have been placed robotically and exteriorized for sewing cuff placement; (B) robotically seated bioprosthetic valve; (C) completed valve replacement with Cor-knot suture attachment (LSI Solutions, Victor, NY, USA). 


\begin{tabular}{|c|c|c|c|c|}
\hline \multicolumn{2}{|c|}{ Posterior leaflet prolapse } & \multirow{2}{*}{$\begin{array}{l}\text { Anterior leaflet } \\
\text { prolapse }\end{array}$} & \multirow{2}{*}{ Bileaflet prolapse (barlow) } & \multirow{2}{*}{ Commissure prolapse } \\
\hline Small segment & Large segment & & & \\
\hline $\begin{array}{l}\text { Triangular } \\
\text { resection }\end{array}$ & Trapezoid resection & $\begin{array}{l}\text { Triangular resection } \\
\text { (small segment) }\end{array}$ & $\begin{array}{l}\mathrm{AL}=\mathrm{PTFE} \text { neochords } \\
\mathrm{PL}=\text { multiple triangular resections }\end{array}$ & $\begin{array}{l}\text { Commissure closure } \\
\text { Alfieri stitch or "magic stitch" }\end{array}$ \\
\hline $\begin{array}{l}\text { PTFE } \\
\text { neochords }\end{array}$ & PTFE neochords & $\begin{array}{l}\text { PTFE neochords } \\
\text { (large segment) }\end{array}$ & $\begin{array}{l}\mathrm{AL}=\mathrm{PTFE} \text { neochords } \\
\mathrm{PL}=\text { multiple folding-plasties }\end{array}$ & PTFE neochords \\
\hline $\begin{array}{l}\text { Native chord } \\
\text { transfer }\end{array}$ & $\begin{array}{l}\text { "Haircut" Edge resection } \\
\text { + native chord transfer or } \\
\text { PTFE neochords }\end{array}$ & $\begin{array}{l}\text { Papillary Folding- } \\
\text { plasty For multiple } \\
\text { chords }\end{array}$ & $\begin{array}{l}\mathrm{AL}=\mathrm{PTFE} \text { neochords } \\
\mathrm{PL}=\text { leaflet sliding-plasty }\end{array}$ & $\begin{array}{l}\text { PL = sliding-plasty + PTFE } \\
\text { neochords }\end{array}$ \\
\hline $\begin{array}{l}\text { Leaflet } \\
\text { folding-plasty }\end{array}$ & Leaflet folding-plasty & $\begin{array}{l}\text { Combined } \\
\text { techniques }\end{array}$ & Combined techniques & $\begin{array}{l}\text { Papillary folding-plasty } \\
\text { (elongated or multi papillary: } \\
\text { PL and AL Chords) }\end{array}$ \\
\hline $\begin{array}{l}\text { Inter-scallop } \\
\text { cleft closure }\end{array}$ & Inter-scallop cleft closure & - & - & - \\
\hline
\end{tabular}

AL, anterior leaflet; PL, posterior leaflet; PTFE, polytetrafluoroethylene.

(XI) Pathology-guided operative techniques used at our center for a RMVP are shown in Table 4 (45);

(XII) A suction vent is passed into the left ventricle. After cardiac de-airing, atrial closure, and cardiopulmonary bypass removal, a detailed TEE study is done.

\section{Major complications}

Patients undergoing a RMVP risk the same complications that can occur with a traditional sternotomy-based operation. However, with the RMVP other complications seem to be inherent in cardiac access, perfusion and ventilation methods used. In over 1,000 robotic cardiac operations, we have never had a complication that was directly related to the daVinci System or the robotic instruments. Our back-up plan for any possible failure has always been either a videoscopic or sternotomy conversion.

(I) Retrograde cardiopulmonary perfusion techniques always induce a risk of atheroembolic strokes, vena caval injury, femoral arterial complications and retrograde aortic dissections. Careful preoperative vascular screening can minimize these problems;

(II) Phrenic nerve injury can be caused by over stretching the pericardium, cautery thermal injury, cryoablation and/or direct instrument injury. This is a major problem in patients with compromised pulmonary function;

(III) Unilateral pulmonary edema is a serious complication. Short perfusion times, avoiding barotrauma, limiting blood product transfusions and minimizing lung deflation times can reduce this risk. We also believe that low level positive pressure and frequent alveolar recruitment, while on cardiopulmonary bypass, is beneficial;

(IV) Trans-thoracic clamp injuries can occur as the posterior element passes near the right pulmonary artery, left main coronary artery and left atrial appendage. Clamp pathway visualization helps prevent these complications. We have had no clamp related aortic dissections in any of our robot-assisted or videoscopic mitral operations;

(V) Right ventricular dysfunction can be minimized. Meticulous cardiac de-airing before weaning from cardiopulmonary bypass is essential. Right thirty-degree chest elevation places the right coronary artery ostium in a perfect position for an air embolism from residual left ventricular air or entrainment during cardioplegia infusions;

(VI) Leg ischemia during retrograde perfusion can be avoided. We place oxygen saturation monitoring patches on both legs. With a significant decrease in cannulated leg oxygen saturation, we place a perfusion shunt in the distal femoral artery. 


\begin{tabular}{lllll}
\begin{tabular}{l} 
Table 5 RMVP postoperative transesophageal studies: residual regurgitation \\
\hline Residual mitral regurgitation
\end{tabular} & All patients N=944 (\%) & RMVP N=675 (\%) & C-RMVP N=231 (\%) & Re-RMVP N=38 (\%) \\
\hline None & 81.8 & 82.4 & 80.1 & 60 \\
Trivial & 15.3 & 15.1 & 16.0 & 36.8 \\
Mild & 2.8 & 2.4 & 3.9 & 2.6 \\
Moderate & 0.7 & 0.0 & 0.9 & 0.0 \\
Severe & 0.1 & 0.0 & 0.0 & 0.0 \\
\hline
\end{tabular}

RMVP, robotic mitral valve repair alone; C-RMVP, CryoMaze + robotic mitral valve repair; Re-MVP, reoperative robotic mitral valve repair.

\section{Operative outcomes}

Results have been published for our first 540 patients. Of these 454 patients underwent a lone mitral repair, and 86 had a concomitant atrial fibrillation ablation. The average cross clamp and cardiopulmonary bypass times were 116 and 153 minutes, respectively, in the lone mitral repair patients. As expected, these times were longer in the patients having a concomitant Maze procedure (130 and 188 minutes, respectively). The group operative mortality was $0.4 \%$ and for a lone operation was $0.2 \%$. Of those treated for preoperative atrial fibrillation, $96.5 \%$ were both atrial fibrillation and drug free at 351 days (15-946 days). During follow-up $2.9 \%$ patients required a re-operation for a failed repair (31).

Since 2000, the author has performed 944 robotassisted mitral valve operations at our institution. This single surgeon's experience subtended the years 20002014 and included the inaugural RMVP series in the United States. The original daVinci, the daVinci S, and the daVinci SI devices all were used in this period. Before the integrated daVinci S and SI fourth arm dynamic retractor, poor trigone visualization from fixed retraction eventuated in several band dislodgements. Trento showed improving results with each new generation of device as did our group (33).

Of the 944 patients, 675 were RMVPs alone, 321 had a concomitant Maze procedure (M-RMVP) and 38 were reoperations (Re-RMVP). Table 4 shows the different techniques that were used for mitral repairs (45). For each of the above cohorts, mean cardiopulmonary perfusion times were 148,187, and 176 minutes, respectively. Mean aortic cross-clamp times were 108 and 128 minutes for RMVP and M-RMVP respective cohorts. Re-RMVP operations were done under hypothermic ventricular fibrillation (113 minutes mean). For the entire series, the in-hospital operative mortality was $1.4 \%$; however, for an isolated RMVP was $0.15 \%$. If a Cryomaze was added, the mortality was significantly higher at $4.7 \%$. We had no mortality in our Re-RMVP patients. Of the entire series $2.5 \%$ had reoperations from a failed repair, which was $1.7 \%$ for a lone RMVP. These were related either to band dehiscence or fibrosis of a posterior leaflet repair.

Major complications included myocardial infarctions in $0.9 \%$ of RMVP patients, which rose to $1.7 \%$ in the adjunctive maze cohort. Strokes occurred in $1.3 \%$ of all patients and were $0.9 \%$ for RMVP patients. This rose to $2.6 \%$ in the M-RMVP cohort. Re-explorations for bleeding were necessary in $2.7 \%, 4.3 \%$, and $5.3 \%$ for RMVP, M-RMVP, and Re-RMVP cohorts, respectively. There were two incidences of phrenic nerve palsy. Packed red cell transfusions were required in $28 \%$ of patients overall and $38 \%$ with any product. Of the RMVP patients, $56.9 \%$ were discharged within 4 days and $75.0 \%$ within 5 days. Table 5 shows post repair trans-esophageal echocardiographic data. For the entire series, $97.1 \%$ of all patients had no or trivial mitral regurgitation when leaving the operating room. Longterm echocardiographic follow-up has not been feasible because of the diverse geographic source of our referrals.

\section{Conclusions and perspective}

Robotic mitral valve repair surgery continues to evolve. Many have challenged the use of robotic valve repairs and replacements. In the past, they have based their concerns on inferior economics, safety, and outcomes. To date, the results of major RMVP series and meta-analyses parallel those of sternotomy operations done by experienced repair surgeons (30-37). Recently, Paul and colleagues reviewed data from 50,408 patients having had any mitral repair in the United States between 2008 and 2012 (35). They compared the 3,145 RMVP patients to all other repair 
operations. Also, they examined a propensity-matched subset of patients. By every analysis, they found no difference in overall cost or complications between the two cohorts. Moreover, the robotic cohort had slightly $(\mathrm{P}=0.048)$ less mortality. The increased cost of robotic instrumentation was offset by a decreased hospital length of stay. Likewise, the Mayo and Cleveland Clinic groups have shown that this type of surgery has definite benefits and can be done within the economic parameters that are demanded today $(27,28)$. The success of these and other groups has been predicated on a finely tuned operative team, experienced mitral repair surgeons, an optimized anesthetic and intensive care system, and an adequate volume of referrals. Robotic mitral repair has become a routine part of their practices. The occasional robotic operation does not provide team cohesion necessary to perform these operations in a coordinated, efficient manner with reasonable operative times. The heart team concept has been adopted at most successful mitral valve referral centers, and asymptomatic patients with severe mitral regurgitation are being referred frequently. This is important as these patients generally have less advanced annular calcific disease, less pulmonary hypertension, better ventricular function, less tricuspid insufficiency and less atrial fibrillation. All of these can add to surgical morbidity and less than satisfactory long-term outcomes.

It is important to select specific patients who will benefit most from this approach. Clearly, sternal access has many advantages in patients with impaired pulmonary and cardiac function as well as other major comorbidities. The RMVP or replacement provides regional, not the global access that has always been beneficial for cardiac air removal, decompression, and topical myocardial protection.

The advancement of 3D trans-esophageal echocardiography has aided mitral repair surgeons greatly. We have applied the measurements shown in Table 2 to create topographic valve models for operative planning. These along with other measurements can be transmitted to the daVinci surgeon console screen for instant review and guidance. Even now, segmented 3D echo images are being used to create life-like printed flexible models of specific valve pathology.

As with any operation there has been an evolutionary quality to robotic mitral repair surgery. As Trento's group has emphasized, these devices have meteorically improved through three generations of the daVinci surgical system $(25,33)$. Better vision and ergonomics as well as development of new instruments have helped improve operative results. Anesthetic and perfusion techniques have improved in parallel. Moreover, the repair techniques that surgeons used 15 years ago have been replaced by limited resections, neochord replacements, and suture fastening devices as well as other repair simplification techniques. These methods are easier to apply in robotic repairs and have been shown to provide either parallel or better outcomes than earlier resection methods (45).

At our institution, we have used the first three versions of daVinci over the past 17 years. We have also used every modification of instruments. Our series shows excellent outcomes in patients who had a lone RMVP with almost zero mortality and very acceptable morbidity. Conversely, compared to other series, we did find that by adding a maze, the mortality, myocardial infarction, and stroke rates increased significantly $(46,47)$. Throughout our experience, we have used all types of ablative energy sources including unipolar radiofrequency, bipolar radiofrequency, microwave, and cryothermia. With the newer cryoprobes and better patient selection, we experienced improvement in mortality and stroke rate in the combined operation. Our retrospective concerns regarding the early Maze patients relate to the use of unipolar radiofrequency and microwave probes, as charring often occurred, potentially increasing the stroke risk. Moreover, longer perfusion times in less well-selected patients probably contributed to a higher mortality. We have not experienced any band dehiscences since we began using the dynamic retractor and braided sutures instead of the "now off-market" U-clips.

Improvements in our outcomes has been an iterative process and predicated on multiple factors. We have been a major teaching center for robotic mitral repair surgery. Thus, many groups have benefited greatly from our developmental experiences and realizations. It is satisfying that programs now can begin without facing the same challenges that we experienced. We believe that a compendium of improvements in technique, devices, imaging, and patient selection will continue to expand the use of robotics in mitral valve repair. Future robotic mitral operations will be customized for each patient and based on their valve pathology, comorbidities, fragility, and age as well as their surgeon's ability. Programmable patient positioning, combined with intraoperative imaging will help align instrument trajectories. The next horizon will include the development of other surgical robots. The economic issue must be addressed, although it can be overcome by process improvement and optimal utilization of the robot. However, there is a cost limit to where a daVinci-like device capital expenditure cannot be justified, even if amortized over several specialties. To be sure, future surgery will 
become more dependent on image guidance, "blueprint" planning, and either catheter-based or robotic types of telemanipulation devices. The less invasive era in cardiac surgery began 20 years ago-I wonder what our specialty will be using in 2036 - the future could be predictable-if we can adapt to change!

"Intelligence is the ability to adapt to change."

Stephen Hawking

\section{Acknowledgements}

This work would not have been possible without the enduring commitment and assistance of Dr. L Wiley Nifong and our ECU Robotic Training Laboratory personnel. He and our team have been my guides since the very beginning in 1999.

\section{Footnote}

Conflicts of Interest: The author has no conflicts of interest to declare.

\section{References}

1. Pompili MF, Stevens JH, Burdon TA, et al. Port-access mitral valve replacement in dogs. J Thorac Cardiovasc Surg 1996;112:1268-74.

2. Fann JI, Pompili MF, Burdon TA, et al. Minimally invasive mitral valve surgery. Semin Thorac Cardiovasc Surg 1997;9:320-30.

3. Navia JL, Cosgrove DM 3rd. Minimally invasive mitral valve operations. Ann Thorac Surg 1996;62:1542-4.

4. Dávila JC. The birth of intracardiac surgery: a semicentennial tribute (June 10, 1948-1998). Ann Thorac Surg 1998;65:1809-20.

5. Harken DE, Glidden EM. Experiments in Intracardiac Surgery. II. Intracardiac Visualization. J Thorac Surg 1943;12:566-72.

6. Sakakibara H, Ichikawa T, Hattori J. An intraoperative method for observation of cardiac septal defect using a cardioscope. Operation 1956;10:285-90.

7. Sakakibara S, Iikawa T, Hattori J, et al. Direct visual operation for aortic stenosis: cardioscopic studies. J Int Coll Surg 1958;29:548-62.

8. Kaneko Y, Kohno T, Ohtsuka T, et al. Video-assisted observation in mitral valve surgery. J Thorac Cardiovasc Surg 1996;111:279-80.
9. Carpentier A, Loulmet D, Aupècle B, et al. Computer assisted open heart surgery. First case operated on with success. C R Acad Sci III 1998;321:437-42.

10. Chitwood WR Jr, Wixon CL, Elbeery JR, et al. Videoassisted minimally invasive mitral valve surgery. J Thorac Cardiovasc Surg 1997;114:773-80; discussion 780-2.

11. Felger JE, Chitwood WR Jr, Nifong LW, et al. Evolution of mitral valve surgery: toward a totally endoscopic approach. Ann Thorac Surg 2001;72:1203-8; discussion 1208-9.

12. Mohr FW, Onnasch JF, Falk V, et al. The evolution of minimally invasive valve surgery--2 year experience. Eur J Cardiothorac Surg 1999;15:233-8; discussion 238-9.

13. Vanermen H, Farhat F, Wellens F, et al. Minimally invasive video-assisted mitral valve surgery: from PortAccess towards a totally endoscopic procedure. J Card Surg 2000;15:51-60.

14. DiMaio S, Hanuschik M, Kreaden U. The daVinci Surgical System in Rosen J, Hannaford B, Satava R (Eds), Surgical Robotics:Systems Applications and Visions. New York: Springer. 2011:199-217.

15. LaPietra A, Grossi EA, Derivaux CC, et al. Roboticassisted instruments enhance minimally invasive mitral valve surgery. Ann Thorac Surg 2000;70:835-8.

16. Autschbach R, Onnasch JF, Falk V, et al. The Leipzig experience with robotic valve surgery. J Card Surg 2000;15:82-7.

17. Chitwood WR Jr, Nifong LW, Elbeery JE, et al. Robotic mitral valve repair: trapezoidal resection and prosthetic annuloplasty with the da vinci surgical system. J Thorac Cardiovasc Surg 2000;120:1171-2.

18. Nifong LW, Chitwood WR, Pappas PS, et al. Robotic mitral valve surgery: a United States multicenter trial. J Thorac Cardiovasc Surg 2005;129:1395-404.

19. Chitwood WR Jr, Rodriguez E, Chu MW, et al. Robotic mitral valve repairs in 300 patients: a single-center experience. J Thorac Cardiovasc Surg 2008;136:436-41.

20. Murphy DA, Miller JS, Langford DA, et al. Endoscopic robotic mitral valve surgery. J Thorac Cardiovasc Surg 2006;132:776-81.

21. Smith JM, Stein H, Engel AM, et al. Totally endoscopic mitral valve repair using a robotic-controlled atrial retractor. Ann Thorac Surg 2007;84:633-7.

22. Murphy D, Smith JM, Siwek L, et al. Multicenter mitral valve study: a lateral approach using the da vinci surgical system. Innovations (Phila) 2007;2:56-61.

23. Mihaljevic T, Jarrett CM, Gillinov AM, et al. Robotic repair of posterior mitral valve prolapse versus conventional approaches: potential realized. J Thorac 
Cardiovasc Surg 2011;141:72-80.e1-4.

24. Trento A. Clinical outcomes associated with robotic repair of the mitral valve. Mayo Clin Proc 2011;86:834-5.

25. Cheng W, Fontana GP, De Robertis MA, et al. Is robotic mitral valve repair a reproducible approach? J Thorac Cardiovasc Surg 2010;139:628-33.

26. Suri RM, Antiel RM, Burkhart HM, et al. Quality of life after early mitral valve repair using conventional and robotic approaches. Ann Thorac Surg 2012;93:761-9.

27. Suri RM, Thompson JE, Burkhart HM, et al. Improving affordability through innovation in the surgical treatment of mitral valve disease. Mayo Clin Proc 2013;88:1075-84.

28. Mihaljevic T, Koprivanac M, Kelava M, et al. Value of robotically assisted surgery for mitral valve disease. JAMA Surg 2014;149:679-86.

29. Suri RM, Burkhart HM, Rehfeldt KH, et al. Robotic mitral valve repair for all categories of leaflet prolapse: improving patient appeal and advancing standard of care. Mayo Clin Proc 2011;86:838-44.

30. Suri RM, Burkhart HM, Daly RC, et al. Robotic mitral valve repair for all prolapse subsets using techniques identical to open valvuloplasty: establishing the benchmark against which percutaneous interventions should be judged. J Thorac Cardiovasc Surg 2011;142:970-9.

31. Nifong LW, Rodriguez E, Chitwood WR Jr. 540 consecutive robotic mitral valve repairs including concomitant atrial fibrillation cryoablation. Ann Thorac Surg 2012;94:38-42; discussion 43.

32. Mihaljevic T, Pattakos G, Gillinov AM, et al. Robotic posterior mitral leaflet repair: neochordal versus resectional techniques. Ann Thorac Surg 2013;95:787-94.

33. Ramzy D, Trento A, Cheng W, et al. Three hundred robotic-assisted mitral valve repairs: the Cedars-Sinai experience. J Thorac Cardiovasc Surg 2014;147:228-35.

34. Yoo JS, Kim JB, Jung SH, et al. Mitral durability after robotic mitral valve repair: analysis of 200 consecutive mitral regurgitation repairs. J Thorac Cardiovasc Surg 2014;148:2773-9.

35. Paul S, Isaacs AJ, Jalbert J, et al. A population-based analysis of robotic-assisted mitral valve repair. Ann Thorac Surg 2015;99:1546-53.

36. Murphy DA, Moss E, Binongo J, et al. The Expanding Role of Endoscopic Robotics in Mitral Valve Surgery: 1,257 Consecutive Procedures. Ann Thorac Surg 2015;100:1675-81; discussion 1681-2.

37. Cao C, Wolfenden H, Liou K, et al. A meta-analysis of robotic vs. conventional mitral valve surgery. Ann Cardiothorac Surg 2015;4:305-14.
38. Joint Task Force on the Management of Valvular Heart Disease of the European Society of Cardiology (ESC); European Association for Cardio-Thoracic Surgery (EACTS), Vahanian A, et al. Guidelines on the management of valvular heart disease (version 2012). Eur Heart J 2012;33:2451-96.

39. Nishimura RA, Otto CM, Bonow RO, et al. 2014 AHA/ ACC guideline for the management of patients with valvular heart disease: executive summary: a report of the American College of Cardiology/American Heart Association Task Force on Practice Guidelines. J Am Coll Cardiol 2014;63:2438-88 and Circulation 2014;129:2440-92.

40. Carpentier A, Adams DH, Filsoufi F. Pathophysiology, preoperative valve analysis, and surgical indications. In:Carpentier A, Adams DH, Filsoufi FCarpentier's Reconstructive Valve Surgery. 1st ed. Maryland Heights, MO: Saunders Elsevier, 2010:43-53.

41. D'Alonzo RC, Gorrin-Rivas MJ, Mackensen GB. Three Dimensional Transesophageal Echocardiographic Planning. New York: Springer;2014:33-54.

42. Chitwood Jr. WR. Atlas of robotic cardiac surgery. New York: Springer, 2014.

43. Kypson AP, Sanderson DA, Nifong LW, et al. Cardiopulmonary Bypass and Myocardial Protection for Minimally Invasive Cardiac Surgery. In: Gravlee GP, Davis RF, Hammon JW, et al. editors. Cardiopulmonary Bypass and Mechanical Support: Principles \& Practice. Philadelphia: Wolters Kluwer, 2016.

44. Bush B, Nifong LW, Alwair H, et al. Video-atlas on robotically assisted mitral valve surgery. Ann Cardiothorac Surg 2013;2:846-8.

45. Chitwood WR. Robotic Mitral Valve Replacement: Techniques and Results.- Robotic Aortic Valve Replacement. In: W. Randolph Chitwood Jr. editor. Atlas of robotic cardiac surgery. London: Springer, 2014.

46. Izumoto H, Kawazoe K, Kitahara H, et al. Can the maze procedure be combined safely with mitral valve repair? J Heart Valve Dis 1997;6:166-70.

47. Ad N, Holmes SD, Pritchard G, et al. Association of operative risk with the outcome of concomitant Cox Maze procedure: a comparison of results across risk groups. J Thorac Cardiovasc Surg 2014;148:3027-33.

Cite this article as: Chitwood WR Jr. Robotic mitral valve surgery: overview, methodology, results, and perspective. Ann Cardiothorac Surg 2016;5(6):544-555. doi: 10.21037/ acs.2016.03.16 